\title{
Association of fetuin-A with kidney disease; a review on current concepts and new data
}

\author{
Marziyeh Akbari $^{1 \oplus}$, Hashem Nayeri ${ }^{{ }^{*}{ }^{\circledR}}$, Hamid Nasri $^{2}$ \\ ${ }^{1}$ Department of Biochemistry, Falavarjan Branch, Islamic Azad University, Isfahan, Iran \\ ${ }^{2}$ Department of Nephrology, Isfahan University of Medical Sciences, Isfahan, Iran
}

\section{A R T I C LE I N F O}

Article Type:

Review

\section{Article History:}

Received: 4 May 2018

Accepted: 15 July 2018

Published online: 5 August 2018

\section{Keywords:}

Fetuin-A

Chronic kidney disease

End-stage renal disease

Type 2 diabetes

\begin{abstract}
A B S T RA C T
Fetuin-A ( $a 2$ Heremans-Schmid glycoprotein) is a glycoprotein which is synthesized in the liver and secreted into the bloodstream. It belongs to a large group of binding proteins mediating the transport and availability of a wide variety of cargo substances in the bloodstream. The aim of this study is to summarize the available results of studies on the association of fetuin-A with chronic kidney disease and end-stage renal disease, type 2 diabetes, non-alcoholic fatty liver, and yield the end results. The databases including PubMed, Google Scholar, Scopus, and Science-Direct were searched with the purpose of finding the related studies. The articles were assessed in terms of repeatability of title, type of study, population, study variables and the quality of reporting. Finally, 37 articles, which were published between the years 2002 and 2018, were selected to be overviewed completely. The studies showed that fetuin-A can function as a protective inhibitor of vascular calcification in patients with chronic kidney disease and end-stage renal disease, and is reduced during acute inflammation. The deficiency of this protein is associated with an increase in the morbidity and mortality of patients with cardiovascular diseases. Fetuin-A can be useful as a vascular disease marker in patients with type 2 diabetes. In fact, it is an independent predictor of type 2 diabetes due to its high concentration in insulin resistance. Fetuin-A is a good indicator of liver cells function and its level will be increased in non-alcoholic fatty liver disease. Fetuin-A, as a multi-functional protein, performs many tasks. However, studies in this area are very limited and based on its multiple and complex functions, further studies are recommended.
\end{abstract}

Implication for health policy/practice/research/medical education:

Fetuin-A can function as a protective inhibitor of vascular calcification in patients with chronic kidney disease and end-stage renal disease, and is reduced during acute inflammation.

Please cite this paper as: Akbari M, Nayeri H, Nasri H. Association of fetuin-A with kidney disease; a review on current concepts and new data. J Nephropharmacol. 2019;8(2):e14. DOI: 10.15171/npj.2019.14.

\section{Introduction}

Fetuin-A is one of the blood proteins which is synthesized in the liver and secreted into the bloodstream. Bovine fetuin-A was first described in 1944 as the large plasma proteins in the fetal bovine serum. Bovine serum has been found to contain more fetuin than albumin, while adult serum contains more albumin than fetuin. This protein was described in humans in 1960 and known as " $\alpha 2$ Heremans-Schmid glycoprotein" (AHSG) (1-3). This name is due to the fraction of alpha 2 globulin of serum proteins in cellulose acetate electrophoresis. In fact, fetuin is a part of a large group of binding proteins mediating the transport and availability of a wide variety of cargo substances in the bloodstream (2). Fetuin-A is a glycoprotein, weighting of $64 \mathrm{kDA}$ that is synthesized in the liver by hepatocytes (1).

Fetuin-A gene exists on chromosomes 3q27 in the human. Fetuin-A is a member of plasma proteins with cystatinlike domains. The domain of cystatin- 1 in fetuin-A has a strong negative charge that has a very high tendency to bind with calcium ion (2).

\section{Materials and Methods}

For this review, we used a variety of sources including PubMed, Google Scholar, Scopus, Science-Direct and directory of open access journals (DOAJ). The search was conducted by using combinations of the following keywords and or their equivalents; fetuin-A, chronic 
kidney disease, end-stage renal disease and type 2 diabetes.

Structure of fetuin-A

Fetuin-A belongs to a class of inhibitors of cysteine proteases, in which they are responsible for bone resorption. The structure consists of one sugar and one protein moiety. Its sugar moiety is composed of two $\mathrm{N}$-glycans and three $\mathrm{O}$-glycans in which its three carbohydrates units are bound to the peptide chain via threonine and serine (4).

\section{Biosynthesis of fetuin-A}

Fetuin-A is a highly expressed liver-derived plasma protein for proteolytic processing, glycosylation, phosphorylation (threonine and serine) which is required for interaction with insulin receptor and the sulfation after translation. Fetuin is processed from a single chain precursor to the mature circulating two-chain form (2).

\section{Biological role of fetuin-A}

Fetuin-A is a multi-functional protein that performs many tasks. Numerous studies have been conducted in this regard. Its function in the human body was evaluated by the technology of transgenic mice. In other words, feeding the fetuin-A gene inactivated mice with a mineral-rich diet leads to extensive calcification in the lungs, heart and kidneys. In fact, the fetuin-A deficiency increases the tendency to calcification throughout the body in rats $(5,6)$. Therefore, fetuin-A is a protective inhibitor of calcification. In other words, fetuin-A is a liver glycoprotein and a potential inhibitor of systemic calcification in the bloodstream, which it will be decreased during acute inflammation (7).

Fetuin-A has a strong tendency to bind to calcium phosphate. Thus it serves as a phosphate-buffered saline (8). Fetuin-A accelerates the addition of exogenous fatty acids to triglycerides. Hence it has a common function with fatty-acid-binding proteins. Similarly, fetuin-A reversibly binds to hydrophobic ligands (including longchain saturated and unsaturated fatty acids and other lipids). Fetuin-A, due to its complicated glycosylation pattern, is used for lectin and glycoprotein researches (2). The anti-inflammatory effects of fetuin-A have been determined in numerous articles. It has been shown that fetuin-A is accompanying with a reduction in inflammatory response and an enhance in life expectancy. It has also been said that the strong expression of fetuin-A, in fetus is associated with the mother's bearing of the fetus. Fetuin-A is considered as one of the negative acute-phase proteins (9). There is a strong correlation between the low serum fetuin-A levels and CRP inflammatory markers. There are a lot of findings showed that fetuin-A may have a protective role in vascular calcification in dialysis patients $(9,10)$. In fact, the deficiency of this protein is accompanying with an intensification in the morbidity and mortality of patients with cardiovascular disease and arterial stiffness in these patients, which accounts for the most popular cause of morbidity and mortality (11-13). Fetuin-A also accounts for about $25 \%$ of the non-collagen protein in bone tissue, which have a high tendency to bind with mature apatite. Fetuin-A is an inhibitor of apatite formation from saturated mineral solvents. It mediates the transport of minerals in extracellular space and blood circulation, too $(12,13)$. Several studies have reported its high concentration in metabolic syndrome, which may be considered as a risk factor for this syndrome (13). Regarding the effect of this protein on insulin receptor, fetuin-A inhibits the tyrosine-kinase function of this receptor then inhibits auto-phosphorylation which finally cause a prevention in its activity.

It has been reported that fetuin-A causes insulin resistance in muscle of adipose tissue. While, in these tissues, its serum concentration is directly associated with insulin resistance due to insulin tyrosine kinase receptor inhibitory impact of fetuin-A.

Fetuin-A can be useful as a vascular disease marker in patients with type 2 diabetes. In fact, it is an independent predictor of type 2 diabetes due to its high concentration in insulin resistance. It is worth saying that a variety of proteins, such as fetuin- $\mathrm{A}$ and adiponectin regulate the insulin sensitivity. Additionally, the association of fetuin-A with atherosclerosis has been mentioned in many cases due to vascular calcification relating to the deficiency of this substance.

\section{Assessment of fetuin-A}

As mentioned, serum fetuin-A concentration is a good indicator of liver cells function. A variety of methods including PCR, immunohistochemistry, immunofluorescence and ELISA have been used to search for fetuin-A in bloodstream or different cells (10,14-16).

\section{Methods}

The databases including PubMed, Google Scholar, Scopus, Science-Direct and directory of open access journals (DOAJ) were searched with the purpose of finding the related studies. Articles from the years 2002 and 2018 were selected and have cross-sectional, case-control, and cohort design. They were then assessed in terms of the title, and the quality of content. Finally, 37articles were selected.

\section{Results}

The relationship of fetuin-A with chronic kidney disease and end-stage renal disease

The proportion of end-stage renal disease (ESRD) patients is estimated to be around 3730000 worldwide at the end of 2016. A total of 2648000 patients are undergoing hemodialysis as the most common treatment. This disease, due to the average annual growth rate of almost $6-5 \%$ in comparison with population growth, is considered as one of the most important health 
problems in all the countries. Cardiovascular disease and stroke are also the leading causes of death in ESRD patients undergoing dialysis $(17,18)$. In the past decade, attentions have focused on the primary cause of death in patients with chronic kidney disease and ESRD (19). Patients undergoing hemodialysis, simultaneously suffer from various complications of dialysis. In dialysis patients, cardiovascular disease and bone diseases are very common and these diseases gradually decrease the quality of life and will increase the morbidity and mortality rate in ESRD (20). The abnormal metabolism of minerals, due to impaired renal function, increases the loss of minerals from the bones and this causes deposition of minerals in arteries (21). The vascular calcification involves arterial stiffness. This condition is associated with a decrease of cardiac function. Typically, phosphate metabolism is regulated by an interaction between kidney, bone and the intestine. This balance is disturbed in renal patients. Calcification is stimulated by disturbances in biochemical factors such as calcium and phosphate, hyperparathyroidism and increased inflammation, while, inhibitors of tissue calcification like fetuin-A improves the vascular consistency (22). In a study conducted by Pertosa et al, 174 ESRD patients undergoing hemodialysis. Around 60 patients (34.5\%) had cardiovascular disease, 20 patients (11.4\%) had diabetes mellitus, 12 patients (7\%) had nephrosclerosis, 17 patients $(9.7 \%)$ had polycystic kidney while 55 patients had unknown diseases. Serum fetuin-A concentration was measured in the group of cardiovascular disease. The results showed a significant reduction in the level of fetuin-A in, cardiovascular disease compared to the control group. The reduction of fetuin-A was accompanying with an increase in the prevalence of cardiovascular and cerebrovascular diseases (23). A crosssectional study conducted by Ketteler et al on 312 patients with CKD over a period of 32 months. The amount of fetuin-A was measured during this time. The low concentration of AHSG was correlated with an increase in the morbidity and mortality caused by inflammation in cardiovascular cells (24). Likewise, a study directed by Smith et al in Melbourne which included 200 participants with CKD, detected vascular calcification is common in patients with chronic renal failure and is considered as a risk factor for this disease. The findings of the study by Altunts et al are important. The study was carried out on 152 individuals with chronic kidney disease who were undergoing regular hemodialysis. Around 61 healthy participants were subjected as the control group. The level of fetuin-A in hemodialysis patients was significantly lower than the control group (25).

\section{The relationship between fetuin-A and type 2 diabetes}

Diabetes is well known as the most common chronic disease worldwide. Based on the average growth rate of diabetes worldwide, the World Health Organization (WHO) described diabetes as an underlying epidemic and all the countries of the world have been called to face this epidemic since 1993.

According to the WHO, the number of people with diabetes in the year 2000 was about 171 million, which would increase up to 366 million in 2030 if appropriate strategies for prevention and treatment were not applied. In the United States, diabetes is now affecting more than $12.3 \%$ of the 20 years old and older population. Identifying new factors in the pathophysiology of diabetes can increase our understanding of the mechanisms which are responsible for individuals' changes relating to the susceptibility of diabetes and provide useful prevention strategies. One of these factors can be fetuin-A $(26,27)$. About the effect of this protein on the insulin receptor $(27,28)$, it has been said that fetuin-A inhibits the tyrosine-kinase function of this receptor and inhibits auto-phosphorylation which these cause a prevention in its activity (Figures 1 and 2). A cohort study was carried out in a multinational study by Aroner et al, in 2017 on African- Americans, Hispanic-Americans, Chinese-Americans and CaucasianAmericans aged between 45 and 84 years old. Among 1957 participants, 455 of them were diabetic. The levels of fat in the liver and fetuin-A were measured. The concentration

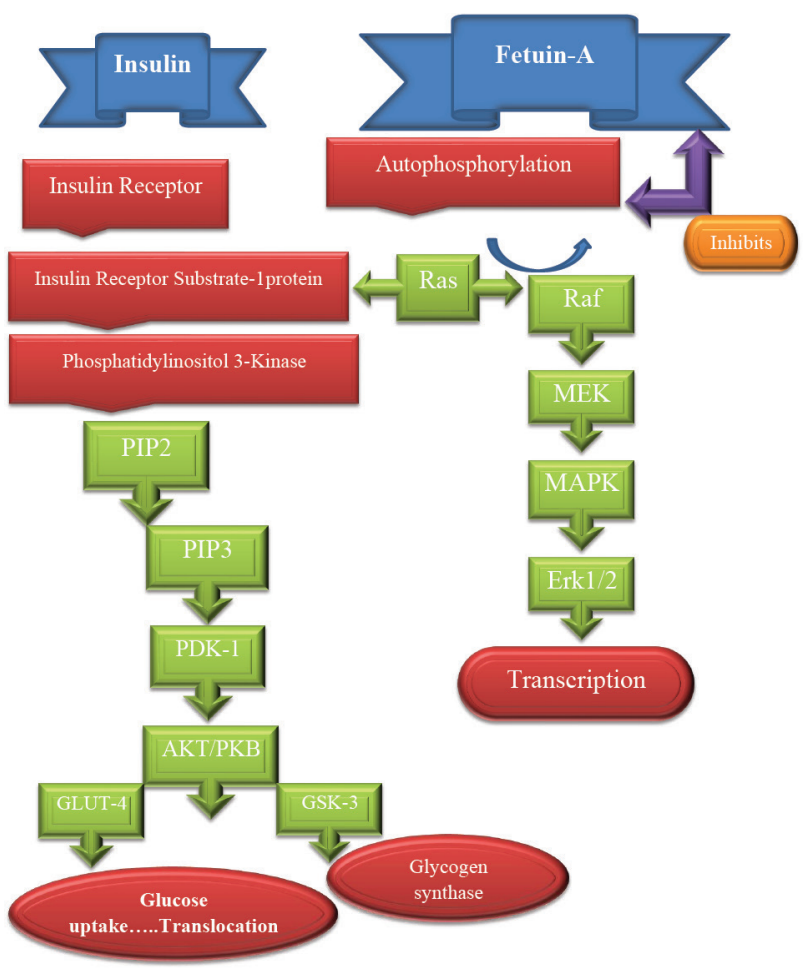

Figure 1. Fetuin-A inhibits the tyrosine-kinase function of insulin receptor and this causes a prevention in its activity. Abbreviations: Renin-angiotensin system (RAS); Phosphatidylinositol 4,5-bisphosphate (PIP2); phosphatidylinositol (3,4,5)-trisphosphate (PIP3); Protein kinase B (PKB); a serine/threonine-specific protein kinase (AKT); Pyruvate dehydrogenase lipoamide kinase isozyme 1(PDK-1); Mitogen-activated protein kinase (MAPK); Extracellular regulated kinases (ERK1/2); Glycogen synthase kinase 3 (GSK-3); Glucose transporter type 4 (GLUT-4). 


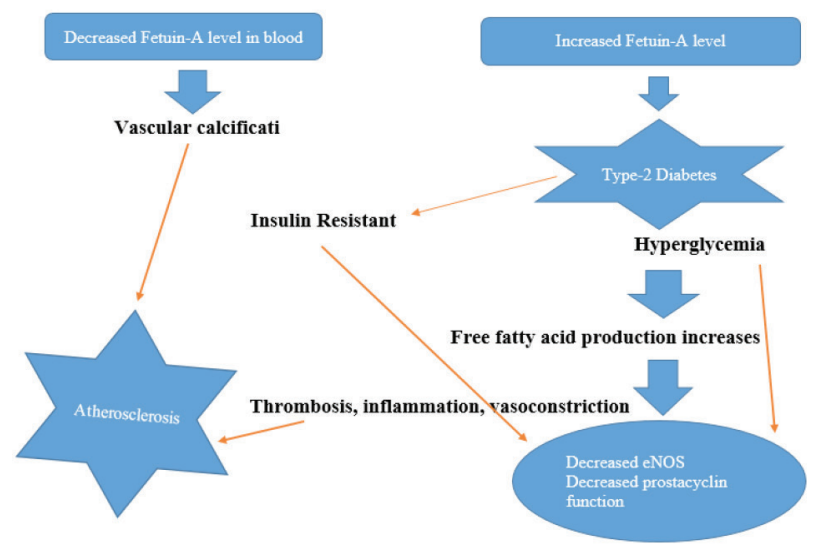

Figure 2. The association of fetuin-A with type 2 diabetes, vascular calcification and atherosclerosis.

of fetuin-A was higher in women with an increase in fat in the liver. The level of fetuin-A, in men after the evaluation for body mass index, smoking, alcohol consumption, and income level was higher when regarding as the risk factor for diabetes (28). Preventive studies were conducted in Europe that were designed for 27548 people. In 2008, Stefan et al, randomly selected 25000 people that 2164 of them were at the beginning phases of diabetes. About 849 diabetic patients were selected during the 7-year follow-up. Around 703 of them participated and were studied. The results showed that an increase in fetuin-A is significantly associated with the risk of diabetes (29). In a study conducted by Jung et al in 2013, 172 individuals with type 2 diabetes participated. About 119 of them were male. The mean age was 52-year-old. They measured insulin resistance, fetuin-A and TNF- $\alpha$. Fetuin-A level was $162 \pm 525 \mu \mathrm{g} / \mathrm{mL}$. There was a positive correlation between an increase in fetuin-A levels with serum levels of adiponectin and TNF-a (30). A study was conducted by Wang et al to detect the relationship between fetuin-A and cardiac valvular calcification. A total of 238 diabetic patients in the present study participated in order to detect vascular calcification by biochemical analysis. The results showed that the levels of fetuin-A and CRP will be increased in diabetes (31). A variety of proteins, such as fetuin- $\mathrm{A}$ and adiponectin regulate the insulin sensitivity. In addition, the association of fetuin-A with atherosclerosis is due to vascular calcification relating to the deficiency of this substance.

\section{Conclusion}

According to studies, and the results of the studies, fetuin-A is a glycoprotein in the liver and a potent inhibitor of vascular calcification in the blood circulation in patients with chronic renal failure and end-stage kidney failure (1-25). It is also known as a vascular disease marker in patients with type 2 diabetes (26-31). It is increased during insulin resistance and non-alcoholic fatty liver, as well (32-37) (Figure 3).

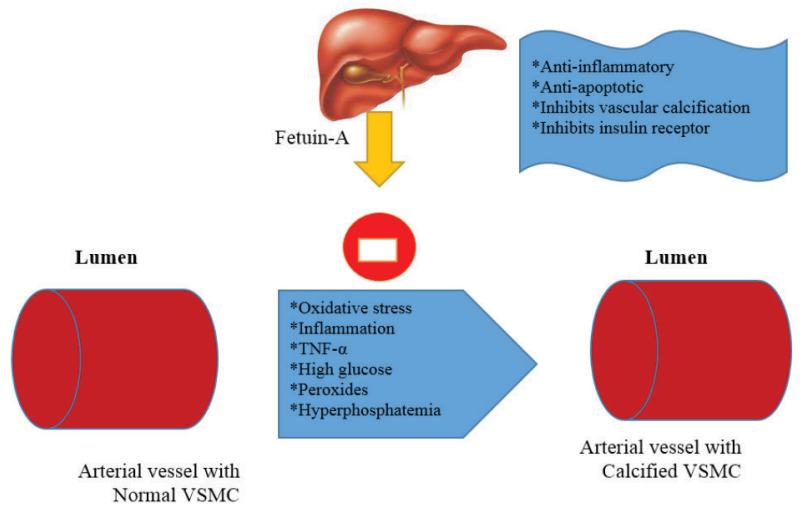

Figure 3. Fetuin-A multi-functions and its relationship with inflammation factors.

It should be pointed out that fetuin-A is still a matter of great interest as an unknown protein and many studies are conducting because of its multiple and complex functions. However, further studies are recommended.

\section{Author's contribution}

MA and H. Nayeri searched the data and prepared the draft of the manuscript. $\mathrm{HN}$ edited and finalized the paper. All authors read and signed the final manuscript.

\section{Conflicts of interest}

The authors declared no competing interests.

\section{Ethical considerations}

Ethical issues (including plagiarism, data fabrication, double publication) have been completely observed by the authors.

\section{Funding/Support}

None.

\section{References}

1. Vörös K, Cseh K, Kalabay L. The role of Fetuin A in cardiovascular diseases. ORV Hetil. 2014;155:16-23. doi: 10.1556/OH.2014.29793.

2. JahnenDechen-t W, Heiss A, Schäfer C, Ketteler M. Fetuin A regulation of calcified matrix metabolism. Circ Res. 2011;108:1494-509. doi: 10.1161/ CIRCRESAHA. 110.234260.

3. Suliman ME, García-López E, Anderstam B, Lindholm B, Stenvinkel P. Vascular calcification inhibitor relation to cardiovascular disease with special emphasis on Fetuin A in chronic kidney disease. Adv Clin Chem. 2008;46:217-62.

4. Arnaud P, Kalabay L. A2HSglycoprotein in search of a function. Diabetes Metab Res Rev. 2002;18:311-4. doi:10.1002/dmrr.315.

5. Moe SM, O'Neill KD, Duan D, Ahmed S, Chen NX, Leapman SB, et al. Medial artery calcification in ESRD patients is associated with deposition of bone $\mathrm{m}$ rix proteins kidney. Kidney Int. 2002;61:638-47. doi: 
10.1046/j.1523-1755.2002.00170.x.

6. London GM, Guérin AP, Marchais SJ, Métivier F, Pannier $\mathrm{B}$, Adda H. Arterial media calcification in end stage renal disease impact on all cause and cardiovascular mortality. Nephrol Dial Transplant. 2003;18:1731-40.

7. Westenfeld R, Jahnen-Dechent W, Ketteler M.vascular calcification and fetuin A deficiency in chronic kidney disease. Trends Cardiovasc Med. 2007;17:124-8.dio: 10.1016/j.tcm.2007.02.005.

8. Joubert P, Ketteler M, Salcedo C, Perello J. Phytate is an important unrecognized nutrient and potential in travenous drug for preventing vascular calcification. Med Hypotheses. 2016;94:89-92.

9. Westenfeld R, Schäfer C, Krüger T, Haarmann C, Schurgers LJ, Reutelingsperger C, et al. FETUIN -A protects against atherosclerotic calcification in CKD. J Am Soc Nephrol. 2009;20:1264-74. doi: 10.1681/ ASN.2008060572.

10. Reynolds JL, Skepper JN, McNair R, Kasama T, Gupta $\mathrm{K}$, Weissberg PL, et al. multifunctional roles for serum protein fetuinA in inhibition of human vascular smooth muscle cell calcification. J Am Soc Nephrol. 2005;16:2920-30. doi: 10.1681/ASN.2004100895

11. Smith ER, Ford ML, Tomlinson LA, Rajkumar C, McMahon LP, Holt SG. Phosphorylated fetuin-A containing calciprotein particles are associated with aortic stiffness and a pro-calcific milieu in patients with per dialysis CKD. Nephrol Dial Transplant. 2012;2:195766. doi: 10.1093/ndt/gfr609.

12. Lichtenauer M, Wernly B, Paar V, Rohm I, Jung C, Yilmaz A, et al. Specifics of fetuin -A levels in distinct types of chronic heart failure. J Clin Lab Anal. 2018; 32.doi: 10.1002/jcla.22179.

13. Scialla JJ, Kao WH, Crainiceanu C, Sozio SM, Oberai PC, Shafi T, et al. Biomarkers of vascular calcification and mortalitying patient. Clin J Am Soc Nephrol. 2014;9:745-55. doi: 10.2215/CJN.05450513.

14. Mehrotra R. Disordered mineral metabolism and vascular calcification in non-dialyzed chronic kidney disease patients. J Ren Nutr. 2006;16:100-18. doi:10.1053/j.jrn.2006.01.006.

15. Kim HI, An WS. Comparison of fetuin-A, vitamin D, monounsaturated fatty acid, and vascular calcification on plain radiography between dialysis modalities. Iran J Kidney Dis. 2013;7:453-60.

16. Singh M, Sharma PK, Garg VK, Mondal SC, Singh AK, Kumar N. Role of fetuin-A in atherosclerosis associated with diabetic patients. J Pharm Pharmacol. 2012;64:1703-8.doi: 10.1111/j.2042-7158.2012.01561.x.

17. Cozzolino M, Galassi A, Bellasi A, Butti A, Zoni U, Gallieni M, et al. Prevention of extra skeletal calcifications in uremia. G Ital Nefrol. 2005;31:S53-5.

18. Suliman ME, García-López E, Anderstam B, Lindholm B, Stenvinkel P. Vascular calcification inhibitor relation to cardiovascular disease with special emphasis on Fetuin A in chronic kidney disease. Adv Clin Chem. 2008;46:217-62.

19. Cozzolino M, Mazzaferro S, Pugliese F, Brancaccio D. Vascular calcification and uremia what dowe know? Am J Nephrol. 2008;28:339-46. doi:10.1159/000111827.
20. Liu M, Li XC, Lu L, Cao Y, Sun RR, Chen S, et al. Cardiovascular disease and its relationship with chronic kidney disease. Eur Rev Med Pharmacol Sci. 2014;18:2918-26.

21. Shioi A, Nishizawa Y. Vascular calcification in chronic kidney disease pathogenesis and clinical implications. J Ren Nutr. 2009;19:78-81. doi: 10.1053/j.jrn.2008.10.015.

22. Schlieper G, Schurgers L, Brandenburg V, Reutelingsperger C, Floege J. Vascular calcification in chronic kidney disease. Nephrol Dial Transplant. 2016;31:31-9. doi: 10.1093/ndt/gfv111.

23. Pertosa G, Simone S, Ciccone M, Porreca S, Zaza G, Dalfino G, et al. Serum Fetuin A in Hemodialysis Alink between Derangement of calcium phosphorus Homeostasis and progression of Atherosclerosis? Am J Kidney Dis. 2009; 53:467-74. doi: 10.1053/j. ajkd.2008.10.046.

24. Ketteler M, Bongartz P, Westenfeld R, Wildberger JE, Mahnken AH, Böhm R, et al. Association of low fetuin A (AHSG) concentration in serum with cardiovascular mortality in patients on dialysis across-sectional study. Lancet. 2003;361:827-33.

25. Altunts A, Yigit A, Inal S, Kidir V, Basri H, Mehment S. The relationship between fetuin A level and fetuin gene polymorphism in hemodialysis patients. Biom Res. 2017; 28:495-502.

26. Shidfar F, Zarrati M, Khamseh ME, Haghighat N, Rostami A, Zolfaghari $H$. Relationship between serum levels of fetuinA with APOA APO B100 baby composition insulin resistance in patients with Type2 diabetes. Med J Islam Repub Iran. 2014;28:100.

27. Yilmaz MI, Saglam M, Qureshi AR, Carrero JJ, Caglar $\mathrm{K}$, Eyileten T, et al. Endothelial dysfunction in type-2 diabetics with early diabetic nephropathy is associated with low circulating adiponectin. Nephrol Dial Transplant. 2008;23:1621-7. doi: 10.1093/ndt/gfm828.

28. Aroner SA, Mukamal KJ, St-Jules DE, Budoff MJ, Katz $\mathrm{R}$, Criqui $\mathrm{MH}$, et al. Fetuin-A and risk of diabetes in dependent of Liver Fat content the multi Ethnic study of Atherosclerosis. Am J Epidemiol. 2017;185:54-64. doi: 10.1093/aje/kww095.

29. Stefan N, Fritsche A, Weikert C, Boeing H, Joost HG, Häring HU, et al. Plasma Fetuin A levels and the risk of Type-2 diabetes. Diabetes. 2008;57:2762-7. doi: 10.2337/ db08-0538.

30. Jung $\mathrm{CH}$, Kim BY, Kim CH, Kang SK, Jung SH, Mok JO. Associations of serum fetuin A levels with insulin resistance and vascular complications in patients with type-2 diabetes. Diab Vasc Dis Res. 2013;10:459-67. doi: $10.1177 / 1479164113490766$.

31. Wang AY, Woo J, Lam CW, Wang M, Chan IH, Gao $\mathrm{P}$, et al. Associations of serum with malnutrition inflammation atherosclerosis and vascular calcification syndrome and outcome in peritoneal dialysis patients. Nephrol Dial Transplant. 2005;20:1676-85. doi:10.1093/ ndt/gfh891.

32. Ferolla SM, Ferrari TC, Lima ML, Reis TO, Tavares WC Jr, Couto OF, et al. Dietary patterns in Brazilian patients with nonalcoholic fatty liver disease across-sectional study. Clinics (Sao Paulo). 2013; 68:11-7. 
33. Hattar LN, Wilson TA, Tabetabo LA, Smith EO, Abrams $\mathrm{SH}$. Physical activity and nutrition attitud inobese Hispanic children with nonalcoholic steatoh epatitis. World J Gastroenterol. 2011;17:4396-403. doi: 10.3748/ wjg.v17.i39.4396

34. Martín-Domínguez V, González-Casas R, MendozaJiménez-Ridruejo J, García-Buey L, Moreno-Otero R. Pathogenesis diagnosis and treatment of nonalcoholic fatty liver disease. RCV ESP Enferm Dig. 2013;105:40920 .

35. Fabbrini E, Sullivan S, Klein S. Obesity and nonalcoholic fatty liver disease: biochemical, metabolic, and clinical implications. Hepatology. 2010;51:679-89. doi: 10.1002/ hep.23280.

36. Hung Y, Bi Y, Ding L, Ehen Y, Peng K, Wang P, et al. Serum fetuin A Associated with fatty liver index Early indicator of nonalcoholic fatty liver disease. Medicine (Baltimore). 2015;94:e1517 doi: 10.1097/ MD.0000000000001517.

37. Cui Z, Xuan R, Yang Y. Nonalcoholic fatty liver disease (NAFLD) serum fetuin A level liver disease in Chinese population. Oncotarget. 2017;8:107149-56. doi: 10.18632 /oncotarget.22361.

Copyright $\odot 2019$ The Author(s); Published by Society of Diabetic Nephropathy Prevention. This is an open-access article distributed under the terms of the Creative Commons Attribution License (http://creativecommons.org/licenses/by/4.0), which permits unrestricted use, distribution, and reproduction in any medium, provided the original work is properly cited. 